had completely disappeared; the large pyramidal cells in the deeper parts of the cortex were less affected but were less numerous than normal. The cells of the neuroglia were more numerous than normal, the vessels were thickened, the pia mater was thickened. The radiating fibres and the short associating fibres passing between adjacent convolutions were much less numerous than normal. There was no coarse lesion, no softening either of the grey matter or of the subjacent white tissue, but the projection fibres of the temporal lobes were notably diminished in number. The external fasciculus of the cerebral peduncle-the fasciculus of Tirckcontained fewer fibres than normal.

This case is one of very great importance. It shows, as Déjerine and Sérieux point out (1) that subcentral (subcortical or subpictorial) word deafness may be due to $a$ purely cortical lesion (hence, as pointed out in the first lecture, the terms "central," "subcentral," and "supracentral" are, I think, better terms than the terms "cortical," "subcortical," and "supracortical"); and (2) that subcentral word deafness is the result (in some cases at least and probably in most cases) of a bilateral lesion which involves, but does not completely destroy, both lower auditory centres. ${ }^{5}$ The lesion was more marked and more advanced in the anterior than in the posterior part of the first temporo-sphenoidal convolution; and in the earlier stages of the case the word deafness merely presented the characteristics of subcentral word deafness, whereas in the later stages of the case (i.e.. when the lesion extended farther back) the symptoms were indicative of central word deafness. The lesion of the lower auditory speech centres must at first have been incomplete, for the patient could hear sounds with the only ear (the left ear) which was available; in the earlier stages of the case she was not deaf but merely word-deaf. If the destruction of both lower auditory centres had at its commencement been complete it would have produced, not merely word deafness, but total deafness.

I may remark in passing that the case has an important bearing on subcortical word blindness; it suggests that subcentral (subcortical) word blindness may, perhaps, in some cases, be due to a cortical lesion which involves, but which does not completely destroy, both half-vision centres. I will return to this point when I come to speak of visual aphasia.

(To be concluded.)

\section{ON THE OCCURRENCE OF METROR- RHAGIA AFTER THE MENOPAUSE IN CASES OF OVARIAN TUMOUR.}

By ARTHUR H. N. LEWERS, M.D. LOND., F.R.C.P. LOND.,

OBSTETRIC PHYSICIAN TO THE LONDON HOSPITALI.

THE recurrence of bleeding from the vagina after the menopause has been definitely established is, in the large majority of cases, as is well known, an indication of the presence of a malignant growth in some part of the genital tract-in the external genitals, in the vagina, or in the cervix or body of the uterus. To give it this unfavourable significance in its fullest extent, however, it is necessary that no doubt should exist that the menopause has actually occurred. This raises the question as to what length of interval without the occurrence of any red vaginal discharge is to be accepted as indicating the establishment of the change of life. I think for practical purposes an interval of two complete years without any sign of menstruation may be accepted as conclusive proof that the menopause has occurred. Any future bl seding after such an interval is to be regarded not as a return of menstruation but as a symptom of the existence of some pathological condition in almost all cases. I say " almost all cases" because, very rarely, some two or three times in the past 20 years, for instance, I have met with a case where bleeding has occurred after the definite establishment of the menopause, in which no evidence of any morbid condition could be found either at the time when the case was first seen or at any subsequent time while the patient continued under observation. Such cases are, however, so

5 Whether subcentral word deafness is always the result of a bilateral lesion remains to be proved by future observation. exceedingly rare that no appreciable consideration need be given to them in ordinary clinical work. In most cases bleeding after the menopause means the presence of a malignant growth. In a small minority of cases, however, such bleeding is due to some morbid condition quite independent of malignant disease. To mention a few of them, it may be due to some fresh changes taking place in a uterine fibroid that has been perhaps altogether quiescent for several years ; it may be due to a mucous polypus, or even to a subacute senile vaginitis, though in both these cases the predominating colour of the discharge is generally yellow with only a moderate, or occasional, admixture of blood in it. It may also be due to a senile endometritis, though here also a free discharge of fresh red blood is not at all common, at all events to anything like the amount that is the rule in cases of cancer. Once again, bleeding after the menopause to a slight extent may be merely due to the ulcers formed on the pro. lapsed parts in cases of prolapse of the uterus and vagina. The last instance to be mentioned is the one that is illus. trated by the three cases recorded in this paper. The growth of an ovarian tumour in patients past the menopause in rare instances causes a discharge of blood from the nterus. Some nine years ago I recorded a case of this kind in THE LANCET. ${ }^{1}$ In that case the bleeding ceased after ovariotomy had been performed and did not recur. This bleeding after the menopause, due to the growth of an ovarian tumour, appears to be a rare occurrence and there is no mention of it in the majority of text-books to which I have referred. While therefore the presence of a red discharge after the menopause should always raise a suspicion of the presence of malignant disease and lead to a careful examination, it is well to bear in mind that in a small percentage of cases the symptom in question may be due to other causes and among these is to be included the growth of an ovarian tumour. Though instances of this appear to be rare, and they are certainly rare in my own experience, yet it happens that I have had three such cases under my care during the past nine months. The notes of these cases are as follows.

CASE 1.-A woman, agcd 60 years, was sent to me by Mr. W. W. Baxter of Manningtree, on Oct. 12th, 1905. She had been married 39 years and had had five children-the last 15 years ago. She had had one miscarriage in the interval between the third and fourth continements. She complained of a feeling of discomfort in the abdomen, which had enlarged in the last four or five months. Stooping gave her pain. She had also had pain on passing urine and micturition had been more frequent than usual during the previous two or three months. This had been so at night as well as in the daytime. The menopause occurred some time shortly before she was 50 years of age and from that timea period of ten years-she had "seen nothing" until a fortnight before she came to me, when she began to have some bleeding from the vagina. On examination a cystic swelling was felt occupying the lower two-thirds of the abdomen. It had some degree of mobility. On vaginal examination there was some recent blood about the parts. The cervix was healthy. The uterus was moveable and seemed separate from the turnour. Soon afterwards she came into a nursing home and I performed ovariotomy on Oct. $26 \mathrm{th}, 1905$. The tumour was a multilocular ovarian cyst of the right ovary. The left ovary was normal. She made an uneventful recovery and went home about a month from the date of the operation. A curious feature subsequent to the operation was the occurrence of an erythema over the abdomen, spreading to the legs and the back, which persisted for about the first ten days after the operation without any rise of temperature.

CASE 2.-A married woman, aged 58 years, was admitted under my care into the London Hospital on Oct. 25th, 1905. She had been married 28 years and had had nine children, the last 11 years previously. She had had no miscarriages. The catamenia appeared when she was between 11 and 12 years old, and she had always been regular every four weeks. The periods generally lasted four or five days. The loss was scanty and had been unattended with pain. The last regular period had occurred seven years previously to her admissionthat is to say, when she was 51 years old-after which there was no red discharge of any kind for four years. Then she noticed a red, or sometimes coffee-coloured, vaginal discharge. With regard to the present illness, she had been conscious of a lump in the abdomen for two years and, as 
mentioned above, she had had a vaginal discharge, which had been sometimes coffee-coloured and at other times bright red, since she was 55 years of age. On admission a somewhat hard swelling was felt occupying the lower abdomen and rising a hand's breadth above the pubes. On vaginal examination there was seen some prolapse of both vaginal walls. The tumour noticed in the lower abdomen could be felt bimanually in the anterior fornix. It felt hard and like a partially calcified fibroid. The sound passed $2 \frac{3}{8}$ inches and on moving it slightly it seemed clear that the uterus was separate from the abdominal tumour described. The uterus seemed quite normal.

Operation was performed on Oct. 31st. Abdomiral section was done in the usual way and the tumour was found to be a fibroid of the left ovary. On section it showed some yellowish patches of degeneration and there were also one or two small cysts seen. The cysts were adjacent to the surface. There were several small patches of calcareous deposit on the surface of the tumour. The tumour had grown from the outer extremity of the ovary and the inner part of the ovary, about half of it, was apparently unaltered. The right ovary was healthy. There was no free fluid in the peritoneal cavity. The patient made an uninterrupted recovery and left the hospital on Nov. $25 \mathrm{th}$.

CASE 3.--A married woman, aged 74 years, was admitted into the London Hospital under my care on March 7th, 1906. She had been married 52 years and had had ten children, the last 30 years ago, and two miscarriages, the last 34 years ago. The catamenia appeared when she was 15 years of age and had always been normal. The menopause occurred at the age of 48 years. Her complaint was that for the three months prior to her admission to the hospital she had had a constant blood-stained discharge from the vagina. From the age of 48 years till three months ago she had had no red or other vaginal discharge at all. She said that she had been getting thinner lately but that her "stomach" had been growing larger. She had lately had to pass urine much more frequently than usual, both during the day and at night. On examination of the abdomen an elastic swelling was felt occupying chiefly the left side of the abdomen; its highest point was two fingers' breadth from the costal margin. On the right side the outline of the tumour corresponded to a line drawn from the umbilicus to the right anterior superior iliac spine. On vaginal examination the vaginal portion of the cervix was normal ; a slight brownish-red discharge was seen in the os. The sound passed through the external os with a slight jerk and could only be passed to the extent of about an inch. Doing this caused no fresh bleeding. A probe a good deal thinner than the uterine sound was then tried and found to pass $2 \frac{1}{2}$ inches. No fresh bleeding was caused by manipulating the probe in the body of the uterus.

Operation was performed on March 9th. Ovariotomy was done and the tumour was found to be a multilocular cyst of the left ovary. The right ovary was much atrophied. Except for a little bronchitis after the operation the patient made an uninterrupted recovery. It is interesting to notice that in this case it was the presence of a red vaginal discharge which attracted the patient's attention and caused her to seek advice.

Harley-street, w.

\section{ON THE VACUOLATED MONONUCLEAR CELLS IN THE BLOOD OF THE GUINEA-PIG.}

[Preliminary Communication.]

By J. C. G. LEDINGHAM, M.B., B.Sc., M.A. Aberd.

(From the Bacteriological Department of the London Hospital and the Lister Institute.)

WhILE investigating the question of leucocytosis in the guinea-pig my attention was directed to the presence in stained films of a peculiar form of mononuclear lencocyte. This leucocyte, while possessing generally the characters of the large mononuclear variety of human hæmatology, had a highly vacuolated cytoplasm and lying in the vacuole, which was in the majority of cases single and of large size, was seen a round, oval, and somewhat irregular mass of finely granular material staining a dull-red with
Leishman's stain. In the literature one finds but few references to the leucocytes of the guinea-pig. Hirschfeld, in 1897, discussed; in Virchow's Archiv the comparative morphology of the white cells of many of the domestic animals, including the guinea-pig, but made no mention of the vacuolated cells. In 1898 Kurloff's work on the part played by the spleen in blood formation and the blood changes after splenectomy appeared in Ehrlich's "Die Anaemie." The guinea-pig was the animal employed and in the course of his description of that animal's leacocytes he makes the following brief reference to the vacuolated cells :-

We find here a peculiar cell group that is characteristic for guinea pig's blood. These cells possess no granulation but in its place we find in the protoplasm a rounded nucleus-like structure which is stained by nuclear dyes and is possibly to be placed in the category of a Nebenkern or accessory nucleus. Our impression was that we had to do with a racuole filled with a secretion product of the cell. Examination of a large series of preparations permits us to form some con clusions regarding the development and fate of these structures. At tirst they appear in the protoplasm as discrete granular dots having no relationship with the cell nucleus. These gradually increase in size and attain considerable dimensions. When they have become as large as the cell nucleus itself thev appear to break through the enveloping cell protoplasm and to quit the cell.

As I was anxious to ascertain whether anything further was known regarding these cells Dr. W. Bulloch kindly wrote on my behalf to Professor Ebrlich who replied that he had not directed his attention for many years to these peculiar structures but that he still thought they represented some "Secrttstotf." He also kindly forwarded a dissertation by Hans Bab on Colostrum Formation which appeared in 1904 and contained some references to the vacuolated cells of the guinea-pig. This author found in film preparations of the marrow and spleen vacuolated cells containing masses of ill-defined granules staining metachromatically with thionin. These cells he preferred to consider as new discoveries on his part but they are undoubtedly identical with those described by Kurloff in the circulating blood. He agreed with Ehrlich that the body represented a mass of granular Sesretstoff.

In the Journal of Medical Research for 1904 Burnett gives a description of the leucocytes of normal guineapigs and makes some references to the vacuolated cells. He states that in fresh blood these bodies are round, homogeneous, and straw-coloured, varying in size from one micron or less to a body occupying nearly half of the cell.

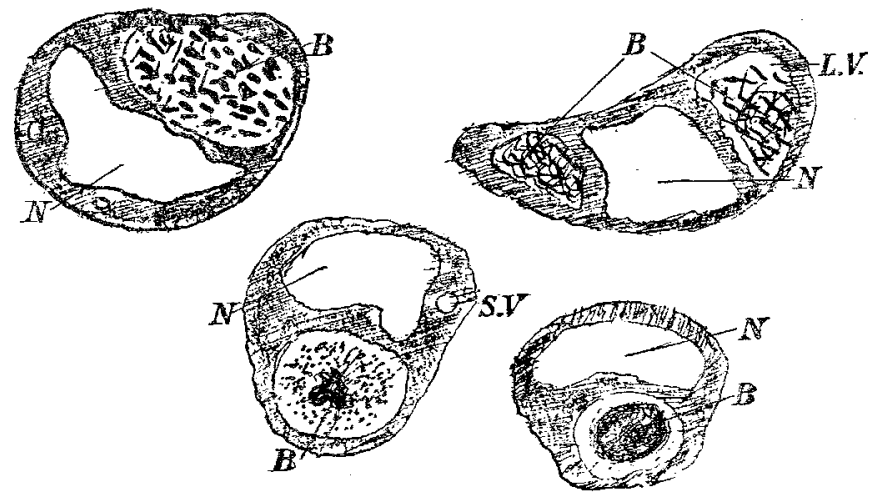

Some types of vacuolated cells as seen in films.

s, Nucleus. B, Body. L.V., Large vacuole. s.v., Small vacuole.

Occasionally true lymphocytes and polynuclear cells were seen with these bodies inside them. In some cases the body presented a clear oval central part, while the peripheral area contained many fine purplish granules (Wright's stain) which seemed to be nodal points of a fine purplish reticulum.

These are all the facts relating to these peculiar structures which $I$ have been able to find in the literature. During the last nine months I have examined numerous films mostly from adult guinea-pigs or, at any rate, from guinea-pigs three months old and upwards. Leishman's and Giemsa's stains were invariably employed. In the majority of the animals the description of the minute structure of the body given by Kurlcti and Burnett holds good. The vacuole was either completely filled with fine granular material or presented an irregular homogeneous central mass with granular radiations extending to the periphery. In some animals, however, a totally different appearance was presented by the body inside the vacuole. With Giemsa's stain after fixation by methyl alcohol the body was found to consist of distinct purplish-staining rods. These latter 